\title{
Non-Injection Drug Use Patterns and History of Injection among Street Youth
}

\author{
Scott E. Hadland ${ }^{a}$ Thomas Kerr ${ }^{b, c}$ Brandon D.L. Marshall ${ }^{b, d}$ William Small $^{b}$ \\ Calvin Lai ${ }^{\mathrm{b}}$ Julio S. Montaner ${ }^{\mathrm{b}, \mathrm{c}}$ Evan Wood ${ }^{\mathrm{b}, \mathrm{c}}$ \\ ${ }^{a}$ Washington University School of Medicine, Saint Louis, Mo., USA; ${ }^{b}$ British Columbia Centre for Excellence in \\ HIV/AIDS, St. Paul's Hospital, ' Faculty of Medicine and ${ }^{d}$ School of Population and Public Health, University of \\ British Columbia, Mather Building, Vancouver, B.C., Canada
}

\section{Key Words}

Street youth $\cdot$ Adolescents $\cdot$ Injection $\cdot$ Drug use $\cdot$ Initiation

\begin{abstract}
Aims: Efforts to prevent youth from initiating injection drug use require an understanding of the drug use patterns that predispose to injecting. Here we identify such patterns and describe the circumstances of first injection among street youth. Methods: From October 2005 to November 2007, data were collected for the At Risk Youth Study, a prospective cohort of 560 street-recruited youth aged 14-26 in Vancouver, Canada. Non-injection drug use behaviors were compared between those with and without a history of injection through multiple logistic regression. The circumstances of first injection were also examined in gender-stratified analyses. Results: Youth who had previously injected were more likely to have engaged in non-injection use of heroin or of crystal methamphetamine. Daily users of marijuana were less likely to have injected. Among prior injectors, the median age of first injection was lower among females. Females were also more likely to have had a sexual partner present at first injection and to have become a regular injector within one week of initiation. Conclusion: Preventing transition to injection among street youth may require special attention to predisposing drug use patterns and should acknowledge gender differences in the circumstances of first injection.

Copyright $\odot 2010$ S. Karger AG, Basel
\end{abstract}

\section{Introduction}

Preventing the initiation of injection drug use is critical to reducing the transmission of blood-borne pathogens such as human immunodeficiency virus (HIV) and curbing other drug-related harm [1-3]. The transition from non-injection to injection drug use, which frequently occurs during adolescence and early adulthood $[4,5]$, remains poorly understood among street youth, a socially and economically disadvantaged population that often eludes population-based studies because of high rates of residential instability [6]. The term 'street youth' is generally applied to adolescents and young adults who spend significant time working or living on the street [7], of whom a large proportion, though not all, are homeless [8]. In multiple locations worldwide, this population reflects a 'hidden' demographic marked by alarmingly high rates of HIV infection [9-11].

Rates of injection drug use are similarly concerning, with one recent multicenter study of Canadian street youth revealing a lifetime prevalence of $22.3 \%$ [12]. Similarly, a nationally representative US survey of homeless youth reported that $17.1 \%$ had previously injected [13]. Based on one recent estimate that Montreal street youth transition to injection at a rate of 8.2 per 100 person-years [14], it is expected that approximately 100 Vancouver street youth initiate injection drug use annually [15]. An accumulating body of evidence suggests that among these

\section{KARGER}

(C) 2010 S. Karger AG, Basel

Fax +4161306 1234 E-Mail karger@karger.ch www.karger.com www.karger.com/ear
Evan Wood, MD, PhD

BC Centre for Excellence in HIV/AIDS, St. Paul's Hospital 608-1081 Burrard Street

Vancouver, BC V6Z 1Y6 (Canada)

Tel. +1 604806 9116, Fax +1 604806 9044, E-Mail uhri-ew@ cfenet.ubc.ca 
youth, those transitioning to injection earlier in adolescence will be more likely to engage in more intense patterns of substance use and risky practices such as receptive syringe sharing $[4,16-18]$.

Public health efforts to prevent the spread of HIV and other drug-related harm could therefore benefit from a better understanding of which specific pre-injection drug use patterns predispose youth to injecting. Several epidemiological studies have indicated that many injection drug users engage in non-injection use of heroin or cocaine before later injecting these same drugs [3, 19-22]. However, many of these studies have focused on older drug users rather than street-recruited youth, who may experience a different pathway to injection drug use [23]. Of the studies that have explicitly examined street youth, almost none have adequately examined how the transition to injection is related to the use of newly emergent or resurgent drugs, such as crystal methamphetamine [24].

Preventative efforts also urgently require an improved understanding of the social and environmental circumstances surrounding first injection experiences of youth $[22,25]$. There may be important gender differences underlying the reasons for transitioning to injection, the other persons present at the time of first injection and the source and safety of equipment used [26]. Female youth, in particular, may be more likely to share injection paraphernalia, placing them at great risk for disease transmission [27]. Better insight into this interplay between drugrelated and interpersonal circumstances at the time of first injection may aid program developers in designing more effective and socially appropriate interventions.

In the present study, we sought to identify non-injection drug use patterns and other sociodemographic characteristics associated with injecting among a cohort of street-recruited youth. We also aimed to describe the circumstances of first injection and highlight important personal and environmental differences that may exist between male and female initiates.

\section{Methods}

\section{Study Sample}

The At Risk Youth Study (ARYS) follows a cohort of youth with extensive street involvement in Vancouver, Canada. The study has been described in detail previously [28]. Recruitment of youth in the present analysis occurred from October 2005 to November 2007. Inclusion criteria for the ARYS study are twofold: (1) 14-26 years of age at the time of enrollment, and (2) use of an illicit drug other than or in addition to marijuana during the 30-day period prior to enrollment. Participants were recruited through extensive street-based outreach methods and subse- quently aided in recruiting others through snowball sampling. Although no explicit inclusion criterion required that youth spend a minimum amount of time on the street or actually live on the street to qualify for the study, in practice, the street-based recruitment produced a sample of youth who spent extensive time on the street, a large proportion of whom were homeless.

At baseline, participants completed an interviewer-administered questionnaire, thus providing sociodemographic data and information on drug- and sex-related behaviors. ARYS was approved by the Research Ethics Board at the University of British Columbia.

\section{Factors Associated with Injection}

The primary outcome, or dependent variable, was having a lifetime history of injection drug use, regardless of the particular drug injected. Independent variables were defined a priori and were selected based on their known effect (i.e. from the literature) or hypothesized effect on the risk of injecting. Specifically, we hypothesized that non-injection drug use patterns and other drug-related behaviors could be identified that are associated with greater odds of injection drug use.

The drug-related independent variables we examined included: non-injection heroin use (ever vs. never), non-injection powder cocaine use (ever vs. never), non-injection crack cocaine use (ever vs. never), non-injection crystal methamphetamine use (ever vs. never), previous daily marijuana use (yes vs. no), positive screen for adolescent drinking behaviors according to the Perceived Benefits of Drinking (PBD) scale ( $\geq 3$ of positive responses vs. $<3$ positive responses), age of first drug use (modeled as a continuous variable) and $\geq$ CAD 50 spent on drugs per day (yes vs. no). Although we were interested in lifetime history for most drug use behaviors, lifetime history of marijuana use was known to be very common in the ARYS cohort, and the cohort was known to have a large subpopulation that had previously engaged in daily usage of marijuana (unpubl. data). For these reasons, we chose to examine daily marijuana usage, rather than lifetime history of usage, as a possible correlate of injection drug use. The PBD scale is a five-item instrument validated among adolescents that examines reasons for drinking and that has been used as a screening tool for alcohol abuse [29].

We also examined a series of sociodemographic and other non-drug-related behavioral variables that, based on earlier studies or our prior hypotheses, could confound the relationship between drug-related variables and risk for injecting. These variables included: gender (male vs. female), current age (modeled as a continuous variable), ethnicity (aboriginal vs. all other ethnicities), prior completion of or current enrollment in high school (yes vs. no), history of homelessness (ever vs. never) and self-reported lifetime history of any form of mental illness (yes vs. no).

We examined this range of drug- and non-drug-related variables in a series of univariate analyses. Univariate analyses employed Pearson's $\chi^{2}$ test for dichotomous variables and the MannWhitney test for continuous variables. Significant covariates $(\mathrm{p}<$ 0.05 ) in univariate analyses were then included in a multiple logistic regression model to examine the adjusted effects of these covariates on the odds of injection drug use.

Describing Circumstances of First Injection

Participants with a history of injection drug use completed an additional section of the ARYS questionnaire pertaining to the 
Table 1. Sociodemographic factors and drug use-related behaviors associated with history of injection drug use among street-involved youth $(\mathrm{n}=560)$

\begin{tabular}{|c|c|c|c|c|c|}
\hline \multirow[t]{2}{*}{ Characteristics } & \multirow[t]{2}{*}{ Total, n (\%) } & \multicolumn{2}{|c|}{ History of injection } & \multirow[t]{2}{*}{ OR $(95 \% \mathrm{CI})$} & \multirow[t]{2}{*}{$\mathrm{p}$} \\
\hline & & $\begin{array}{l}\text { yes, n (\%) } \\
(\mathrm{n}=230)\end{array}$ & $\begin{array}{l}\text { no, n (\%) } \\
(\mathrm{n}=330)\end{array}$ & & \\
\hline \multicolumn{6}{|l|}{ Sociodemographic factors } \\
\hline Male & $381(68.0)$ & $163(70.9)$ & $218(66.1)$ & $1.25(0.87-1.80)$ & 0.230 \\
\hline Median age (IQR) & $22(21-24)$ & $23(21-25)$ & $21(19-23)$ & $1.26(1.18-1.35)$ & $<0.001$ \\
\hline Aboriginal ethnicity & $131(23.4)$ & $51(22.2)$ & $80(24.2)$ & $0.89(0.60-1.33)$ & 0.570 \\
\hline High school education $^{1}$ & $231(41.3)$ & $77(33.5)$ & $154(46.7)$ & $0.58(0.41-0.82)$ & 0.002 \\
\hline Ever homeless & $512(91.4)$ & $220(95.7)$ & $292(88.5)$ & $2.86(1.40-5.87)$ & 0.004 \\
\hline History of mental illness & $222(39.6)$ & $105(45.7)$ & $117(35.5)$ & $1.53(1.08-2.16)$ & 0.015 \\
\hline \multicolumn{6}{|l|}{ Drug use-related behaviors } \\
\hline Non-injection heroin use $\mathrm{e}^{2}$ & $274(48.9)$ & $169(73.5)$ & $105(31.8)$ & $5.94(4.09-8.62)$ & $<0.001$ \\
\hline Non-injection cocaine use $\mathrm{e}^{2}$ & $447(79.8)$ & $196(85.2)$ & $251(76.1)$ & $1.81(1.16-2.83)$ & 0.008 \\
\hline Non-injection crack use $\mathrm{e}^{2}$ & $427(76.3)$ & $205(89.1)$ & $222(67.3)$ & $3.99(2.48-6.41)$ & $<0.001$ \\
\hline Non-injection crystal methamphetamine use ${ }^{2}$ & $395(70.5)$ & $197(85.7)$ & $198(60.0)$ & $3.98(2.59-6.11)$ & $<0.001$ \\
\hline Daily marijuana use & $284(50.7)$ & $105(45.7)$ & $179(54.2)$ & $0.71(0.51-0.99)$ & 0.046 \\
\hline Drinking behaviors ${ }^{3}$ & $275(49.1)$ & $118(51.3)$ & $157(47.6)$ & $1.16(0.83-1.63)$ & 0.385 \\
\hline Age of first drug use (IQR) & $13(11-14)$ & $12(10-13)$ & $13(11-14)$ & $1.56(1.11-2.20)$ & $<0.001$ \\
\hline$\geq$ CAD 50 spent on drugs daily & $252(45.0)$ & $113(49.1)$ & $139(42.1)$ & $1.31(0.93-1.85)$ & 0.122 \\
\hline
\end{tabular}

circumstances surrounding their first injection. Participants were stratified by gender to examine differences between males and females. Pearson's $\chi^{2}$ test was used to examine differences in proportions, except where expected cell counts were fewer than five; in these cases, Fisher's exact probability test was used.

\section{Analysis}

We performed all statistical analyses using SAS version 9.1 (SAS Institute Inc., Cary, N.C., USA) and Intercooled Stata 10.0 (StataCorp LP, College Station, Tex., USA). All reported p values are two-sided and considered significant at $\mathrm{p}<0.05$.

\section{Results}

From October 2005 to November 2007, 560 youth were recruited into the ARYS cohort. Among participants, the median age was 22 years [interquartile range (IQR): $21-$ 24 years], 381 (68.0\%) were male, and 397 (70.9\%) were white. Of the remaining 163 non-white participants, 131 (80.4\%) were aboriginal. The cohort spent a median of 12 hours on the street per day (IQR: 6-24 h).

\section{Factors Associated with Injection}

Of 560 ARYS participants, 230 (41.1\%) had previously injected drugs, including 163 males (70.9\%) and $67 \mathrm{fe}-$ males (29.1\%). Of the remaining participants who had never injected, 291 (88.2\%) reported that they were 'very unlikely' to try, 10 (3.0\%) were 'unlikely', 5 (1.5\%) were 'neutral', 1 (0.3\%) was 'likely', $3(0.9 \%)$ were 'very likely', and $20(6.1 \%)$ declined to respond.

Univariate relationships between the outcome (lifetime history of injection drug use) and independent variables (sociodemographic factors and drug use-related behaviors) are shown in table 1 . Those more likely to have a history of injection were older, had not completed and were not currently enrolled in high school, had a history of homelessness, and a history of mental illness. Drug userelated behaviors associated with a history of injection included non-injection use of heroin, cocaine, crack and crystal methamphetamine, as well as an earlier age of first drug use. A sixth behavior, daily usage of marijuana, was associated with decreased odds of prior injection.

Table 2 provides unadjusted odds ratios for all covariates as obtained from the univariate analyses, as well as adjusted odds ratios for all covariates included in the 
Table 2. Multivariate associations between sociodemographic factors and drug use-related behaviors and injection drug use among street-involved youth

\begin{tabular}{|c|c|c|}
\hline Characteristics & Adjusted OR (95\% CI) & $\mathrm{p}$ \\
\hline \multicolumn{3}{|l|}{ Sociodemographic factors } \\
\hline Age (per year increase) & $1.19(1.11-1.30)$ & $<0.001$ \\
\hline High school education $^{1}$ & $0.76(0.50-1.15)$ & 0.187 \\
\hline Ever homeless & $1.77(0.76-4.08)$ & 0.176 \\
\hline History of mental illness & $1.43(0.95-2.14)$ & 0.079 \\
\hline \multicolumn{3}{|l|}{ Drug use-related behaviors } \\
\hline Non-injection heroin use $\mathrm{e}^{2}$ & $3.71(2.44-5.64)$ & $<0.001$ \\
\hline Non-injection cocaine use ${ }^{2}$ & $0.90(0.52-1.56)$ & 0.710 \\
\hline Non-injection crack use ${ }^{2}$ & $1.57(0.87-2.82)$ & 0.131 \\
\hline \multicolumn{3}{|l|}{ Non-injection crystal } \\
\hline methamphetamine use ${ }^{2}$ & $2.60(1.57-4.31)$ & $<0.001$ \\
\hline Daily marijuana use & $0.63(0.42-0.94)$ & 0.033 \\
\hline \multicolumn{3}{|l|}{ Age of first drug use } \\
\hline (per year decrease) & $1.34(0.88-2.02)$ & 0.166 \\
\hline
\end{tabular}

multivariate analysis. Variables that were significant at $\mathrm{p}<0.05$ in univariate analyses and, therefore, included in the multivariate model were older age at study enrollment, high school education, history of homelessness, history of mental illness, prior non-injection heroin use, prior non-injection cocaine use, prior non-injection crack use, prior non-injection crystal methamphetamine use, daily marijuana use and earlier age of first drug use. All factors were associated with increased odds of injection except for two, high school education and daily marijuana use, which were associated with decreased odds. In multiple logistic regression, four factors remained significantly associated with lifetime injection history. Three of these factors were associated with greater odds of injection and included older age, non-injection heroin use and non-injection crystal methamphetamine use; the fourth, daily marijuana use, was associated with decreased odds of injection, even despite intensive covariate adjustment.

\section{Circumstances of First Injection}

Table 3 illustrates the circumstances of first injection stratified by gender. As noted in the table, the median age of first injection was significantly lower for females than for males. Others present at the time of first injection also differed significantly between males and females, with females having a sexual partner present much more frequently than males. Additionally, females were signifi- cantly more likely to become regular injectors (defined as injecting at least once weekly thereafter) within one week of their first injection than males.

\section{Discussion}

In the present study, we observed that approximately two-fifths of street youth had previously engaged in injection drug use. Furthermore prior injection was independently associated with older age and non-injection use of heroin and crystal methamphetamine, an increasingly prevalent drug among high-risk youth [24]. Of note, youth engaging in daily use of marijuana were significantly less likely to have a history of injection, and this difference persisted despite intensive covariate adjustment. Upon closer examination of the circumstances of first injection among the cohort, we found that the median age of first injection was significantly lower for females than for males, and that females were more likely than males to have a sexual partner present for their first injection. Seventy percent of all injecting youth had previously used the same substance they injected in a noninjection form, and all but a few experienced little difficulty obtaining a needle, with family, friends or acquaintances being the most common source. Importantly, nearly half of all females became regular injectors within one week of their first injection, while fewer than onethird of males ultimately became regular injectors.

The high risk of transition to injection among streetinvolved users of heroin and cocaine (including crack) is supported by several other studies [14, 17, 19]. It appears that growing dependence on a drug through non-injection routes of administration is a common impetus for transitioning to injection $[23,30]$. That neither non-injection use of cocaine nor of crack was associated with a history of injection in our sample may represent a dynamic unique to the Vancouver street youth population. However, both variables were strongly associated with injection drug use in the univariate analyses, only to lose significance in the multivariate analysis. This phenomenon might be explained by the high rate of polysubstance use among participants; that is, users of non-injection heroin or crystal methamphetamine might have also been more likely to use non-injection cocaine or crack, and variable adjustment in the multivariate model would have caused these variables to lose significance. Future studies should further characterize the role of these drugs in transitioning to injecting and explore the possibility of regional differences in their effects. 
Table 3. Circumstances of first injection among male and female youth with a history of injection drug use $(\mathrm{n}=230)$

\begin{tabular}{|c|c|c|c|c|}
\hline \multirow[t]{2}{*}{ Characteristics } & \multirow{2}{*}{$\begin{array}{l}\text { Total, } \\
\text { n (\%) }\end{array}$} & \multicolumn{2}{|l|}{ Gender } & \multirow[t]{2}{*}{$\mathrm{p}$} \\
\hline & & $\begin{array}{l}\text { male, } n(\%) \\
(\mathrm{n}=163)\end{array}$ & $\begin{array}{l}\text { female, } n(\%) \\
(n=67)\end{array}$ & \\
\hline Median age first injection (IQR) & $17(15-19)$ & $18(16-20)$ & $17(15-18)$ & 0.022 \\
\hline First drug injected & & & & 0.222 \\
\hline Cocaine & $57(24.8)$ & $40(24.5)$ & $17(25.4)$ & \\
\hline Heroin & $46(20.0)$ & $27(16.6)$ & $19(28.4)$ & \\
\hline Crack & $45(19.6)$ & $36(22.1)$ & $9(13.4)$ & \\
\hline Heroin and methamphetamine & $29(12.6)$ & $23(14.1)$ & $6(9.0)$ & \\
\hline Dilaudid or morphine & $24(10.4)$ & $18(11.0)$ & $6(9.0)$ & \\
\hline Crystal methamphetamine & $16(7.0)$ & $9(5.5)$ & $7(10.5)$ & \\
\hline Other & $13(5.7)$ & $10(6.1)$ & $3(4.5)$ & \\
\hline Prior non-injection use of drug & & & & 0.065 \\
\hline Yes & $162(70.4)$ & $109(66.9)$ & $53(79.1)$ & \\
\hline $\mathrm{No}$ & $68(29.6)$ & $54(33.1)$ & $14(20.9)$ & \\
\hline Condition at time of injection & & & & 0.128 \\
\hline Sober & $151(65.7)$ & $109(66.9)$ & $42(62.7)$ & \\
\hline High on drugs & $55(23.9)$ & $34(20.9)$ & $21(31.3)$ & \\
\hline Alcohol intoxication & $24(10.4)$ & $20(12.3)$ & $4(6.0)$ & \\
\hline Others present at first injection & & & & 0.007 \\
\hline Family, friend or acquaintance & $182(79.1)$ & $136(83.4)$ & $46(68.7)$ & \\
\hline Sexual partner & $30(13.0)$ & $14(8.6)$ & $16(23.9)$ & \\
\hline Alone & $18(7.8)$ & $13(8.0)$ & $5(7.5)$ & \\
\hline Ease of obtaining needle ${ }^{1}$ & & & & 0.960 \\
\hline Very easy & $196(86.3)$ & $140(87.0)$ & $56(86.2)$ & \\
\hline Easy & $26(11.5)$ & $18(11.2)$ & $8(12.3)$ & \\
\hline Somewhat hard or very hard & $4(1.8)$ & $3(1.9)$ & $1(1.5)$ & \\
\hline Source of needle $e^{1}$ & & & & 0.547 \\
\hline Family, friend or acquaintance & $123(53.5)$ & $89(54.6)$ & $34(50.8)$ & \\
\hline Needle exchange program & $36(15.7)$ & $26(16.0)$ & $10(14.9)$ & \\
\hline Dealer & $26(11.3)$ & $19(11.7)$ & $7(10.4)$ & \\
\hline Sexual partner & $25(10.9)$ & $14(8.6)$ & $11(16.4)$ & \\
\hline Pharmacy & $20(8.7)$ & $15(9.2)$ & $5(7.5)$ & \\
\hline Became a regular user ${ }^{2}$ & & & & 0.013 \\
\hline Within one week & $81(35.2)$ & $48(29.5)$ & $33(49.3)$ & \\
\hline After at least one week & $88(38.3)$ & $66(40.5)$ & $22(32.8)$ & \\
\hline Never & $61(26.5)$ & $49(30.1)$ & $12(17.9)$ & \\
\hline
\end{tabular}

${ }^{1}$ Data were missing for two males and one female for these questions.

2 Defined as using injection drugs at least once per week thereafter.

Use of crystal methamphetamine, a drug strongly associated with injection drug use in our analysis, is at once highly prevalent among street youth and vastly understudied [28]. In particular, smoking crystal methamphetamine is common among street youth and the drug remains readily available in many settings despite great efforts to reduce its supply and regulate sales of its precursors [31,32]. Its increasingly prevalent use is particularly concerning in light of one recent report suggesting that female methamphetamine injectors, when compared to their non-methamphetamine-injecting peers, may engage in high-risk behaviors, such as receptive syringe sharing, unprotected sex and maintaining multiple sexual partners, more frequently [33]. Our findings thus reinforce the great need for innovative approaches to curbing crystal methamphetamine use and its associated harms. Little data exists on the efficacy of maintenance therapies for the treatment of stimulant dependence, but 
some evidence exists that heroin substitution programs may be effective at reducing initiation into injection [34]. Recruiting street youth for such interventions, however, may prove especially difficult. Currently, one of the most commonly employed points of contact with at-risk youth is the judicial system, and methamphetamine-using youth in particular appear more likely than their peers to have a history of incarceration and to have interactions with police [24]. However, imprisonment of high-risk youth carries costs that probably far exceed those of addiction treatment $[35,36]$, and may in fact be associated with greater transition to injection drug use $[4,5]$. In this light, greater efforts might be made to intervene early with street youth before they have negative interactions with police, and to develop alternative criminal justice interventions so that high-risk youth can be directed to addiction services rather than to prison.

That daily users of marijuana were less likely to have injected also requires careful consideration. A plausible explanation for this is that frequent marijuana users may represent a different subpopulation of street youth who, for multiple reasons, are uninterested in injection drug use. One recent qualitative study identified a group of street youth in Montreal who explicitly avoid the use of drugs such as heroin and cocaine that, in their opinion, are highly addictive and ultimately lead to drug dependence [23]. Instead, these youth prefer 'softer', more 'pleasurable' drugs such as hallucinogens, the casual use of which they do not view as interfering with eventual life goals. The small proportion of these youth who had attempted injection for a short time quickly returned to hallucinogens, expressing concerns about becoming dependent and losing control. Some of the daily marijuanausing youth in our cohort may self-identify in a similar manner, viewing their drug use as pleasure-seeking in nature and remaining uninterested in drugs such as heroin, cocaine and crystal methamphetamine, which they view as riskier substances. Therefore, an additional interpretation of our results is that some of the marijuana-using youth in our study had actually tried other psychoactive drugs for a short period of time and decided not to continue, whereas the prior injectors had tried these same drugs, enjoyed them and ultimately progressed to injection drug use.

Regardless, whether our findings directly contradict the traditional view of marijuana as a 'gateway' drug that is, a drug whose use precipitates the use of harder and more addictive drugs - merits additional study. Among one recent cohort of adult injection drug users, those who had transitioned to injection drug use prior to the age of
21 years were more likely to have smoked marijuana in the two years prior to their first injection than those transitioning at an older age [19]. Although some might argue that this supports a 'gateway' theory of marijuana, an alternative argument deserves consideration. Conceivably, marijuana use superimposed on a certain set of personal and environmental risk factors, such as young age, thrillseeking and early exposure to abuse, or other traumatic events, family conflict or substance abuse among parents, could predispose youth to a steep trajectory towards the heavy and frequent use of harder drugs $[5,22,23$, $37-39]$. By this same token, youth using marijuana in the absence of these risk factors would be less likely to progress to injection. In any case, future studies should thoroughly examine how the relationship between marijuana and subsequent transition to injection might be modified by such risk factors.

Like other earlier studies, we have demonstrated that the first injection experience varies between male and female first-time injectors [26, 37, 40-43]. Our findings that female youth first inject in general a full year earlier than males and that females are more likely to have a sexual partner present at the time of first injection may support the conclusion that some females are coerced into injecting [44]. Alternatively, others have previously argued that the probability of a female having a sexual partner present at the time of first injection is greater simply because female injection drug users are more likely to have integrated sex and drug-using networks [45, 46]. Regardless of the underlying explanation, our findings also suggest that female youth may be more likely to become regular users within days of their first injection, thus highlighting the central importance of this experience for later drug use patterns. This is particularly concerning given the emerging recognition that for many initiates, future injection risk behaviors, including sharing needles and other paraphernalia, are established at the time of their first injection $[18,26]$. As has been suggested previously, interventions to reduce the harms of injection may therefore benefit from a dual approach, aiming not only to prevent the transition to injection drug use, but also to provide current and potential injection drug users with the risk-negotiating skills and other resources necessary to protect themselves from disease when they do inject [26].

There are several limitations to the present study. First, because street youth represent a 'hidden' demographic elusive to population-based sampling procedures, we employed extensive street-based outreach with snowball sampling, an approach that does not produce a truly ran- 
dom sample. However, it is noteworthy that the characteristics of our cohort are similar to those of other samples of street youth studied in western Canada. For example, one sample of street youth studied in Vancouver demonstrated a lifetime prevalence of injection drug use of $37.8 \%$ (as compared to $41.1 \%$ in our study) [47]. Second, our study primarily drew from self-reported information, and given the sensitive nature of many questions, there may have been some degree of socially desirable reporting among the youth interviewed, even despite our efforts to assure confidentiality and build trust with all participants [48]. The effect of this would be to underestimate the true prevalence of some of the risk behaviors examined. Third, our sample had a median age of 22 years, and our results should be interpreted with the understanding that our cohort may have been slightly older on average than those of other studies of street youth. Fourth, because our analyses drew on cross-sectional data, it is inappropriate to generate conclusions regarding temporality and causation based on the findings of our study alone.

In summary, this study builds on existing evidence by extending principles regarding the transition to injection drug use among older users to street youth. It also highlights the risk for injection among crystal methamphetamine users, a subgroup of street youth that has largely eluded epidemiologic study, and illustrates important gender differences in the circumstances of first injection among street youth. This population remains at once understudied and underserved, but represents an important target population for interventions aimed at reducing risk behaviors, particularly those related to the transmission of blood-borne pathogens such as HIV. Our findings suggest that an increased focus on the non-injection use of heroin and crystal methamphetamine may be required to prevent the transition to injection among street youth. Moreover, efforts to mitigate injection-related harm might re-examine the influence of sexual partners on injection practices among female street youth, and heed the substantially increased risk of becoming a regular injector in the time immediately following young women's first injections.

\section{Acknowledgements}

We thank the ARYS participants for their willingness to be included in the study, as well as current and past ARYS investigators and staff. We also acknowledge Deborah Graham, Tricia Collingham, Leslie Rae, Caitlin Johnston and Steve Kain for their assistance in research and administration.

This study was supported by the US National Institutes of Health (RO1 DA011591) and the Canadian Institutes of Health Research (HHP-67262). Dr. Kerr is additionally supported by the Michael Smith Foundation for Health Research (MSFHR) and the Canadian Institutes of Health Research. Mr. Marshall is supported by a Canada Graduate Scholarship from CIHR and a Senior Graduate Trainee Award from MSFHR. None of the aforementioned organizations had any further role in study design, the collection, analysis or interpretation of data, in the writing of the report, or the decision to submit the work for publication.

\section{Conflict of Interest Statement}

Dr. Montaner has received educational grants from, served as an ad hoc advisor to or spoken at various events sponsored by Abbott Laboratories, Agouron Pharmaceuticals Inc., Boehringer Ingelheim Pharmaceuticals Inc., Borean Pharma AS, Bristol-Myers Squibb, DuPont Pharma, Gilead Sciences, GlaxoSmithKline, Hoffmann-La Roche, Immune Response Corporation, Incyte, Janssen-Ortho Inc., Kucera Pharmaceutical Company, Merck Frosst Laboratories, Pfizer Canada Inc., Sanofi Pasteur, Shire Biochem Inc., Tibotec Pharmaceuticals Ltd. and Trimeris Inc.

\section{References}

1 HIV Prevention Bulletin: Medical advice for persons who inject illicit drugs. Washington DC, Public Health Service, US Department of Health and Human Services, 1997. http:// www.cdcnpin.org/reports/medadv.pdf (accessed Oct. 23, 2008).

$\checkmark 2$ Des Jarlais DC, Friedman SR: HIV infection among intravenous drug users: epidemiology and risk reduction. AIDS 1987;1:67-76.

-3 Vlahov D, Fuller CM, Ompad DC, Galea S, Des Jarlais DC: Updating the infection risk reduction hierarchy: preventing transition into injection. J Urban Health 2004;81:1419.

Injection Drug Use among Street Youth
4 Fuller CM, Borrell LN, Latkin CA, Galea S, Ompad DC, Strathdee SA, Vlahov D: Effects of race, neighborhood, and social network on age at initiation of injection drug use. Am J Public Health 2005;95:689-695.

$\checkmark 5$ Miller CL, Strathdee SA, Kerr T, Li K, Wood E: Factors associated with early adolescent initiation into injection drug use: implications for intervention programs. J Adolesc Health 2006;38:462-464.
6 Farrow JA, Deisher RW, Brown R, Kulig JW, Kipke MD: Health and health needs of homeless and runaway youth. A position paper of the Society for Adolescent Medicine. J Adolesc Health 1992;13:717-726.

7 The State of the World's Children 1997. Oxford and New York,: UNICEF, 1997. http:// www.unicef.org/sowc97/download.htm (accessed July 10, 2009).

8 Brannigan A, Caputo T: Studying Runaways and Street Youth in Canada: Conceptual and Research Design Issues. Ottawa, Canada Ministry of Supply and Services, 1993. 
$\checkmark 9$ Kissin DM, Zapata L, Yorick R, Vinogradova EN, Volkova GV, Cherkassova E, Lynch A, Leigh J, Jamieson DJ, Marchbanks PA, Hillis $\mathrm{S}$ : HIV seroprevalence in street youth, $\mathrm{St}$. Petersburg, Russia. AIDS 2007;21:2333-2340.

10 Pfeifer RW, Oliver J: A study of HIV seroprevalence in a group of homeless youth in Hollywood, California. J Adolesc Health 1997;20:339-342.

-11 Roy E, Haley N, Leclerc P, Sochanski B, Boudreau JF, Boivin JF: Mortality in a cohort of street youth in Montreal. JAMA 2004;292: 569-574.

12 Street youth in Canada: findings from the enhanced surveillance of Canadian street youth, 1999-2003. Ottawa, Public Health Agency of Canada, 2006. http://www.phacaspc.gc.ca/std-mts/reports_06/pdf/street_ youth_e.pdf (accessed 16 Jun 2009).

13 Greene JM, Ennett ST, Ringwalt CL: Substance use among runaway and homeless youth in three national samples. Am J Public Health 1997;87:229-235.

14 Roy E, Haley N, Leclerc P, Cedras L, Blais L, Boivin JF: Drug injection among street youths in Montreal: predictors of initiation. J Urban Health 2003;80:92-105.

-15 Kerr T, Tyndall MW, Zhang R, Lai C, Montaner JS, Wood E: Circumstances of first injection among illicit drug users accessing a medically supervised safer injection facility. Am J Public Health 2007;97:1228-1230.

16 Battjes RJ, Leukefeld CG, Pickens RW: Age at first injection and HIV risk among intravenous drug users. Am J Drug Alcohol Abuse 1992;18:263-273.

-17 Neaigus A, Miller M, Friedman SR, Hagen DL, Sifaneck SJ, Ildefonso G, des Jarlais DC: Potential risk factors for the transition to injecting among non-injecting heroin users: a comparison of former injectors and never injectors. Addiction 2001;96:847-860.

-18 Novelli LA, Sherman SG, Havens JR, Strathdee SA, Sapun M: Circumstances surrounding the first injection experience and their association with future syringe sharing behaviors in young urban injection drug users. Drug Alcohol Depend 2005;77:303-309.

-19 Fuller CM, Vlahov D, Arria AM, Ompad DC, Garfein R, Strathdee SA: Factors associated with adolescent initiation of injection drug use. Public Health Rep 2001;116(suppl 1):136-145.

20 Griffiths P, Gossop M, Powis B, Strang J: Transitions in patterns of heroin administration: a study of heroin chasers and heroin injectors. Addiction 1994;89:301-309.

-21 Irwin KL, Edlin BR, Faruque S, McCoy HV, Word C, Serrano Y, Inciardi J, Bowser B, Holmberg SD: Crack cocaine smokers who turn to drug injection: characteristics, factors associated with injection, and implications for HIV transmission. The Multicenter Crack Cocaine and HIV Infection Study Team. Drug Alcohol Depend 1996;42:8592.
22 Roy E, Haley N, Leclerc P, Cedras L, Boivin JF: Drug injection among street youth: the first time. Addiction 2002;97:1003-1009.

23 Roy E, Nonn E, Haley N: Transition to injection drug use among street youth - a qualitative analysis. Drug Alcohol Depend 2008;94: 19-29.

24 Wood E, Stoltz JA, Zhang R, Strathdee SA, Montaner JS, Kerr T: Circumstances of first crystal methamphetamine use and initiation of injection drug use among high-risk youth. Drug Alcohol Rev 2008;27:270-276.

25 Clatts MC, Goldsamt L, Neaigus A, Welle DL: The social course of drug injection and sexual activity among YMSM and other high-risk youth: an agenda for future research. J Urban Health 2003;80(4 suppl 3): iii26-iii39.

26 Frajzyngier V, Neaigus A, Gyarmathy VA, Miller M, Friedman SR: Gender differences in injection risk behaviors at the first injection episode. Drug Alcohol Depend 2007;89: 145-152.

27 Lloyd-Smith E, Kerr T, Zhang R, Montaner JSG, Wood E: High prevalence of syringe sharing among street involved youth. Addict Res Theory 2008; 16:353-358.

28 Wood E, Stoltz JA, Montaner JSG, Kerr T: Evaluating methamphetamine use and risks of injection initiation among street youth the ARYS study. Harm Reduct J 2006;3:18.

29 Petchers MK, Singer MI: Perceived-Benefitof-Drinking Scale: approach to screening for adolescent alcohol abuse. J Pediatr 1987;110 977-981.

30 Harocopos A, Goldsamt LA, Kobrak P, Jost JJ, Clatts MC: New injectors and the social context of injection initiation. Int J Drug Policy 2009;20:317-323.

-31 Reuter P, Caulkins JP: Does precursor regulation make a difference? Addiction 2003; 98:1177-1179.

32 Wood E, Tyndall MW, Spittal PM, Li K, Anis AH, Hogg RS, Montaner JS, O’Shaughnessy MV, Schechter MT: Impact of supply-side policies for control of illicit drugs in the face of the AIDS and overdose epidemics: investigation of a massive heroin seizure. CMAJ 2003;168:165-169.

33 Lorvick J, Martinez A, Gee L, Kral AH: Sexual and injection risk among women who inject methamphetamine in San Francisco. J Urban Health 2006;83:497-505.

34 Nordt C, Stohler R: Incidence of heroin use in Zurich, Switzerland: a treatment case register analysis. Lancet 2006;367:1830-1834.

35 Hadland SE, Kerr T, Li K, Montaner JS, Wood E: Access to drug and alcohol treatment among a cohort of street-involved youth. Drug Alcohol Depend 2009;101:1-7.

36 Wood E, Kerr T, Spittal PM, Tyndall MW, O'Shaughnessy MV, Schechter MT: The healthcare and fiscal costs of the illicit drug use epidemic: the impact of conventional drug control strategies and the impact of a comprehensive approach. BCMJ 2003;45: 130-136.
37 Draus PJ, Carlson RG: Needles in the haystacks: the social context of initiation to heroin injection in rural Ohio. Subst Use Misuse 2006;41:1111-1124.

38 Ompad DC, Ikeda RM, Shah N, Fuller CM, Bailey S, Morse E, Kerndt P, Maslow C, Wu Y, Vlahov D, Garfein R, Strathdee SA: Childhood sexual abuse and age at initiation of injection drug use. Am J Public Health 2005; 95:703-709.

-39 Sherman SG, Fuller CM, Shah N, Ompad DV, Vlahov D, Strathdee SA: Correlates of initiation of injection drug use among young drug users in Baltimore, Maryland: the need for early intervention. J Psychoactive Drugs 2005;37:437-443.

40 Crofts N, Louie R, Rosenthal D, Jolley D: The first hit: circumstances surrounding initiation into injecting. Addiction 1996;91:11871196.

41 Diaz T, Vlahov D, Edwards V, Conover S, Monterroso E: Sex-Specific Differences in Circumstances of Initiation into InjectingDrug Use Among Young Adult Latinos in Harlem, New York City. AIDS Behav 2002;6: 117-122.

42 Doherty MC, Garfein RS, Monterroso E, Latkin C, Vlahov D: Gender differences in the initiation of injection drug use among young adults. J Urban Health 2000;77:396414.

$\checkmark 43$ Evans JL, Hahn JA, Page-Shafer K, Lum PJ, Stein ES, Davidson PJ, Moss AR: Gender differences in sexual and injection risk behavior among active young injection drug users in San Francisco (the UFO Study). J Urban Health 2003;80:137-146.

$\checkmark 44$ Bourgois P, Prince B, Moss A: The everyday violence of hepatitis $\mathrm{C}$ among young women who inject drugs in San Francisco. Hum Organ 2004;63:253-264.

45 Kane S: HIV, heroin and heterosexual relations. Soc Sci Med 1991;32:1037-1050.

-46 Latkin CA, Mandell W, Knowlton AR, Doherty MC, Vlahov D, Suh T, Celentano DD: Gender differences in injection-related behaviors among injection drug users in Baltimore, Maryland. AIDS Educ Prev 1998;10: 257-263.

47 Ochnio JJ, Patrick D, Ho M, Talling DN, Dobson SR: Past infection with hepatitis A virus among Vancouver street youth, injection drug users and men who have sex with men: implications for vaccination programs. CMAJ 2001;165:293-297.

-48 Des Jarlais DC, Sloboda Z, Friedman SR, Tempalski B, McKnight C, Braine N: Diffusion of the D.A.R.E and syringe exchange programs. Am J Public Health 2006;96: 1354-1358. 